\title{
CASE SUMMARY OF ADRENOCORTICAL CARCINOMA IN A NIGERIAN WOMAN
}

${ }^{1}$ Akinyele Akinlade, ${ }^{1}$ Abdulwaid Saliu, ${ }^{1}$ Benjamin Odusanya, ${ }^{1}$ Taiwo Owoseni, ${ }^{1}$ Olumide Alao, ${ }^{1}$ Olugbenga Oyewole,

${ }^{1}$ Oritseweyinmi Dottie, ${ }^{1}$ Oluwafemi Ogunbadewa, ${ }^{1}$ Surajudeen Quadri, ${ }^{2}$ Michael Olamoyegun, ${ }^{3}$ Ofem Enang ${ }^{1}$ Genera; Hospital Odan, Lagos; '2Ladoke Akintola University Teaching Hospital Ogbomosho, Oyo State; ${ }^{3}$ University of Calabar

Teaching Hospital Calabar, Cross River State

BACKGROUND

Adrenocortical carcinoma $(\mathrm{AC})$ is relatively rare $(0.02-0.2 \%$ of all cancer-related deaths), and can have protean clinical manifestations. Majority of cases are metastatic at the time of diagnosis, with the local periadrenal tissue, lymph nodes, lungs, liver, and bone as commonest sites of spread. Early detection of tumors is crucial for curative resection

\section{CASE}

A 63-year old Nigerian businesswoman was found to have a large right adrenal tumor while being investigated for chronic anemia. She is a known hypertensive for about 10 years controlled with Nifedipine. Younger sister died from adrenal cancer in the USA 2 years earlier.

She was admitted into the hospital because of complaints of profound tiredness, poor appetite and poor sleep and for investigation of the chronic anemia. Her hematocrit level had dropped from 31 to $22.3 \%$ within 2 months. There were no indications of chronic blood loss from the GIT or par vaginam and no renal disease.

Her examination showed in addition to palor, a large right hypochondrial/loin mass

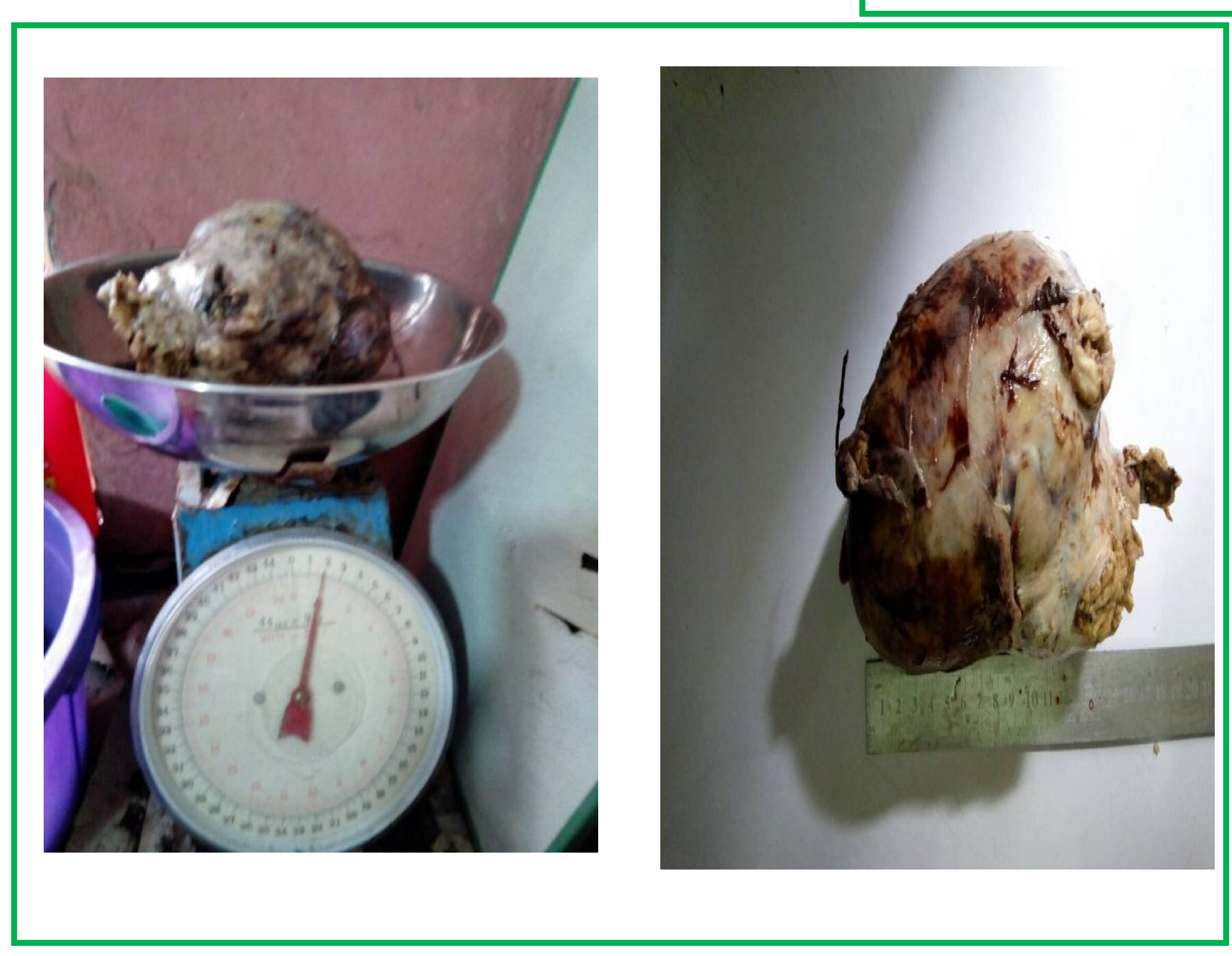

MANAGEMENT

RESULTS

Abdominal USS and CT scan showed was a large solid right suprarenal mass $(13.8 \mathrm{~cm} \times 12.8 \times 12.1 \mathrm{~cm})$ with a few calcific foci (soft tissue density $30-40 \mathrm{HU}$ ) and compressing the right kidney and liver. Postcontrast, there was mild heterogenous, predominantly peripheral enhancement with central non-enhancing area (soft tissue density $40-70 \mathrm{HU}$ ). Multiple abnormal vascular channels were seen within the mass. But no obvious invasion of visualized abdominal organs or surrounding right renal vein or IVC.

Except for hypokalemia and low-normal magnesium, serum/plasma sodium, phosphate,calcium, aldosterone, rennin, TSH, cortisol, metanephrine and normetanephrine were within normal limits.
At surgery, a solid well encapsulated adrenal mass with no macroscopic fat, weighing $2000 \mathrm{~g}$ was removed and histology findings were those of adrenocortical carcinoma.
The hypokalemia that was corrected with spironolactone and $\mathrm{KCl}$ (both oral and infusion) and also had magnesium supplement.
She is being followed up by the oncologist, surgeons and physicians at the out-patient clinics and has so far done well

\section{HISTOPATHOLOGY}

